\section{Tropical Journal of Pathology and Microbiology}

2021 Volume 7 Number 3 May-June

\title{
Manifestations of Bone Marrow Abnormalities of HIV/AIDS Patients
}

\author{
Kanti Pramanik S. ${ }^{1 *}$, Guha Mallick Sinha M. ${ }^{2}$ \\ DOI: https://doi.org/10.17511/jopm.2021.i03.05 \\ 1* Soumya Kanti Pramanik, Post Graduate Trainee, Department of Pathology, Institution of Post Graduate Medical Education \& Research, \\ Kolkata, West Bengal, India. \\ 2 Mamata Guha Mallick Sinha, Professor and Head, Department of Pathology, Institution of Post Graduate Medical Education \& Research, \\ Kolkata, West Bengal, India.
}

Background: Human immunodeficiency virus can involve almost any organ system. Anemia is the most common hematological manifestation in HIV/AIDS patients. Bone marrow changes include varying degrees of dysplasia in one or more cell lines, plasmacytosis, opportunistic infections and hematological malignancies. There are only a few studies where hematological manifestations of HIV/AIDS patients had been described. Materials and Methods: 100 HIV positive patients, aged between 12-65 years were enrolled in this hospital-based cross-sectional study. The study was conducted from March 2016 to March 2018. A complete blood count, CD4 counts were done, besides a thorough history and clinical examination. HIV positive patients were classified as those having AIDS and Non-AIDS, according to NACO criteria. Written informed consent was taken from patients and bone marrow aspiration was done. Results: Total number of patients included in the study was 100. We were able to do a CD4 count of 91 patients. As per criteria, out of 91 patients, 37 cases had AIDS. The most common hematological abnormality was anemia, seen in $95.45 \%$ of patients. Bone marrow was normocellular in $86.48 \%$ of AIDS and $85.18 \%$ of non-AIDS, hypocellular in $8.10 \%$ of AIDS and $9.25 \%$ o non- AIDS, hypercellular in $5.40 \%$ of AIDS and $5.55 \%$ of non-AIDS patients. Dysplasia was statistically and significantly associated with anemia. The commonest dysplastic features are seen in the granulocytic and erythroid series. L.D. bodies were seen in 2 cases and Histoplasma was found in one case. Conclusion: Normocytic normochromic anemia was the most common peripheral smear finding. Hypocellular bone marrow was more common than hypercellular marrow in an advanced stage of the disease. Dysplastic changes were more common in AIDS than Non-AIDS. Granulocytic dysplasia was the most common type of dysplasia. There was evidence of opportunistic infections and gelatinous transformation were detected in our study.

Keywords: Hematology, Bone marrow, Myelodysplasia, Leishmaniasis, Histoplasma, Gelatinous transformation, HIV

Corresponding Author

Soumya Kanti Pramanik, Post Graduate Trainee, Department of Pathology, Institution of Post Graduate Medical Education \& Research, Kolkata, West Bengal, India.

Email: soumyasskm@gmail.com

\section{How to Cite this Article}

Pramanik SK, Sinha MGM. Manifestations of Bone Marrow Abnormalities of HIV/AIDS Patients. Trop J Pathol Microbiol. 2021;7(3):119-127. Available From https://pathology.medresearch.in/index.php/jopm/ar ticle/view/536

\section{To Browse}

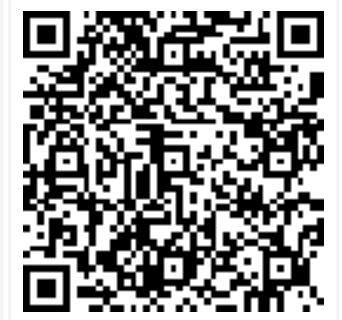

Manuscript Received 2021-06-03

Conflict of Interest No

Review Round 1
2021-06-10
Funding
Nil

- Funding

() 2021 by Soumya Kanti Pramanik, Mamata Guha Mallick Sinha and Published by Siddharth Health Research and Social Welfare Society. This is an Open Access article licensed under a Creative Commons Attribution 4.0 International License https://creativecommons.org/licenses/by/4.0/ unported [CC BY 4.0].

\begin{tabular}{|c|c|}
\hline $\begin{array}{c}\text { Review Round } 2 \\
2021-06-16\end{array}$ & $\begin{array}{c}\text { Review Round } 3 \\
2021-06-22\end{array}$ \\
\hline $\begin{array}{c}\text { Ethical Approval } \\
\text { Yes }\end{array}$ & $\begin{array}{c}\text { Plagiarism } \mathbf{X} \text {-checker } \\
5 \%\end{array}$ \\
\hline
\end{tabular}

Accepted 2021-06-26

Note 


\section{Introduction}

Human immunodeficiency virus infection has emerged as a major health problem worldwide. Acquired immunodeficiency virus was isolated from a patient with lymphadenopathy in 1983. By 1984, HIV was demonstrated to be the causative agent of AIDS [1]. India has an estimated 2.5 million HIV infections and worldwide approximately 2.7 million people are getting newly infected with this virus every year [2].

Infection with human immunodeficiency virus type 1 (HIV-1) primarily involves a subgroup of $\mathrm{T}$ lymphocytes(CD4+ve), but infection of marrow mesenchymal stem cells with HIV has been incriminated as an important factor causing bone marrow defects[3]. Reduced colony growth factors have been demonstrated for granulocytemacrophage progenitor cells and megakaryocyte progenitor cells in most patients with AIDS. As a result of HIV infection, the marrow produces a histiocytic reaction which varies from the increased number of histiocytes to full-blown hemophagocytic syndrome with severe pancytopenia [4].

The most common finding of bone marrow is anemia. Bone marrow findings include trilineage dysplasia, increased eosinophils and plasma cells, increased iron and reticulin fibrosis. These abnormalities may be due to the direct toxic effect of the virus on progenitor cells, ineffective hematopoiesis, immune mechanism and drug reactions[5].

Several opportunistic infections are common HIV infected patients like tuberculosis, histoplasmosis, cryptococcosis, leishmaniasis, coccoidiomycosis and toxoplasmosis [6].

Kaposi's sarcoma, NHL, primary CNS lymphoma and invasive cervical carcinoma- these are the four AIDS-defining malignancies [7]. NHLs are encountered when the CD4 count is < $100 /$ microliter. There are several pathogenetic mechanisms of $\mathrm{NHL}$, among them -progressive impairment of dendritic cell function, EBV infection and mutations resulting in deregulation of BCL- 6 proto-oncogenes are important[8].

Here, in our study, we aimed to identify the bone marrow abnormalities in patients with HIV disease, who admitted to Government medical colleges and hospitals and attending ART clinics. Both patients on ART and Non ART were included in the present study.

\section{Materials and Methods}

The setting of the study: The study was conducted at the Department of Medicine and Department of Pathology, Institute of Post Graduate Medical Education and Research, Kolkata, West Bengal.

Duration of the study: The study was conducted over 2 years, between March 2016 to March 2018.

Type of Study: A prospective descriptive clinical study.

Sampling method: All HIV positive patients (those who satisfied the inclusion and exclusion criteria), both symptomatic and asymptomatic, reporting to antiretroviral therapy centre and admitted to a tertiary care institution of West Bengal were included within the study. HIV was diagnosed by the ELISA method as per NACO guidelines.

Sample size calculation: A total of 100 HIV patients were included in the study.

Inclusion criteria: Indoor patients from medicine wards and those attending ART clinics included in the study.

Exclusion criteria: Patients of malignancy not related to HIV disease and patients receivingchemotherapy were excluded.

Data Collection Procedure: Detailed history was taken which mainly included age, sex, place of residence, occupation, history of blood or blood product transfusions, high-risk behavior, fever, weight loss, diarrhoea, oral or genital ulcerations, bleeding diathesis or history suggestive of systemic involvement. All patients were subjected to thorough physical examination both, systemic and general with necessary investigations like CD4 count, Complete Hemogram by cell counter, USG abdomen, CSF examination, CT scan etc.

Definition of AIDS and other parameters: HIV was diagnosed by the ELISA method as per NACO guidelines. All patients were classified as those having AIDS (CD4 $\leq 200 / \mu \mathrm{L}$ ) and Non-AIDS (CD4 > $200 / \mu \mathrm{L}$ ), according to NACO criteria. Hematologic parameters were obtained by Sysmex KX-21 automated cell counter.In our study, Anemia is defined as hemoglobin level less than $10 \mathrm{gm} / \mathrm{dl}$. Leucopenia was defined as a total count less than 4000 cells/cumm, Neutropenia was defined as absolute neutrophil count $<1000$ cells/cumm. 
Lymphopenia was considered when absolute lymphocyte count $<800$ cells/cumm. and thrombocytopenia was defined as a platelet count less than $1.5 \mathrm{lac} / \mathrm{cumm}$.

Bone Marrow Study: Bone marrow examination was performed for indication of anemia, leucopenia, pancytopenia and thrombocytopenia. Bone marrow aspirate was obtained after informed consent from HIV/AIDS patients. Bone marrow was aspirated with the help of Salah's and Klima'sbone marrow aspiration needle from the posterior superior iliac spine under local anesthesia and antiseptic precautions. In selected cases, bone marrow biopsies were also performed with the help of the Jamshidi needle.

Slides were prepared from marrow particles and were fixed in absolute methanol. Smears were routinely stained with Leishman stain, Perl's Prussian blue stain and acid-fast stain. Periodic Acid Schiff stain was done in selected cases.Bone marrow sample was examined for cellularity, morphologic data including myeloid cell, erythroblast, megakaryocyte, lymphocyte, plasma cell, histiocyte, dysplastic changes, and fibrosis, granuloma and iron stores.

Other investigations performed were hemoglobin, total leucocyte count, differential leukocyte counts, absolute neutrophil, lymphocyte, monocyte, eosinophil and basophil counts, general blood picture, platelet count, reticulocyte count, mean corpuscular volume, mean corpuscular hemoglobin, mean corpuscular hemoglobin concentration and total red blood cell count.

Ethical Considerations and Permission: The patient's consent and ethical clearance were obtained before starting the study.

Statistical analysis: Results were tabulated in a Microsoft office excel worksheet and expressed in mean \pm standard deviation for continuously distributed variables and in absolute numbers and percentages for discrete variables. Appropriate standard statistical methods were utilized. ChiSquare Test, T-test and $\mathrm{p}$-value were analyzed. A Pvalue of less than 0.05 was considered significant.

Any scoring system: Grading of iron stores on bone marrow aspiration was done as documented by Gale et.

Surgical Procedure: No.

\section{Result}

We had included 100 patients detected as HIV positive by ELISA method, reporting to ICTC clinic and admitted in medicine ward of our institution.

Table 1: Age distribution of patients.

\begin{tabular}{|l|l|l|}
\hline \multicolumn{1}{|c|}{ Age Groups } & \multicolumn{1}{c|}{ Number of Patients } & \multicolumn{1}{c|}{$\%$} \\
\hline 12 to 20 years & 2 & 2 \\
\hline 21 to 30 years & 43 & 43 \\
\hline 31 to 40 years & 39 & 39 \\
\hline 41 to 50 years & 10 & 10 \\
\hline 51 to 60 years & 4 & 4 \\
\hline 61 and above & 2 & 2 \\
\hline Total & 100 & 100 \\
\hline
\end{tabular}

The commonest age group involved, was 21 to 40 years $(82 \%)$, similar findings were reported from other studies. [Table 1] Out of 100 HIV positive patients, 87 were male and 13 were female patients. There was a male preponderance with a male to female ratio of $6.69: 1$.

Pie Chart 1: Occupation of patients.

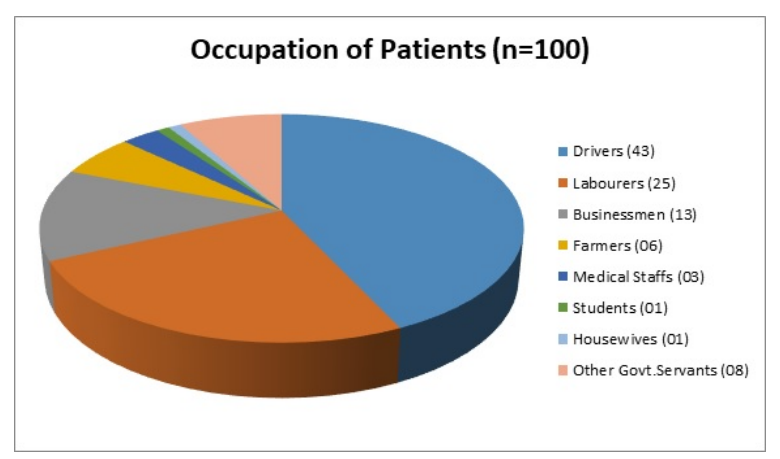

The commonest population affected was that of drivers (43\%) and labourers (25\%) [Pie Chart 1]

Table 2: CD4 Counts.

\begin{tabular}{|l|l|l|}
\hline \multicolumn{1}{|c|}{ CD4 Counts } & \multicolumn{1}{c|}{ No. of patients $(\mathbf{n = 9 1 )}$} & $\%$ \\
\hline$<200$ (AIDS) & 37 & 40.65 \\
\hline$>200$ (Non-AIDS) & 54 & 59.34 \\
\hline
\end{tabular}

All cases were divided into two groups' on-ART and Non-ART with 62 and 38 patients respectively. CD4 count could be done in 91 out of 100 patients due to technical difficulty and financial problems. In that 37 patient's CD4 counts $<200 /$ microliter considered as AIDS according to the CDC criteria and 54 patients CD4 counts $>200 /$ microliter considered as NonAIDS [Table 2].

Anemia ( $\mathrm{Hb} \%<10 \mathrm{~g} / \mathrm{dl}$ ) was found in $95.45 \%$ cases, of this normocytic normochromic in $77.25 \%$. 
Almost, the same percentage of patients belonging to the Non-AIDS group were suffering from anemia.

Table 3: Values, standard deviation and significance of bone marrow parameters.

(NS = Not significant, $S=$ Significant, $H S=$ Highly significant).

\begin{tabular}{|c|c|c|c|}
\hline $\begin{array}{c}\text { Hematological } \\
\text { Parameters }\end{array}$ & $\begin{array}{c}\text { AIDS Mean } \pm \text { SD } \\
(n=37)\end{array}$ & $\begin{array}{c}\text { Non-AIDS Mean } \pm \\
\text { SD }(n=54)\end{array}$ & Values \\
\hline Hemoglobin\% (g/dl) & $8.50 \pm 1.40$ & $9.12 \pm 0.59$ & $\begin{array}{l}0.0878 \\
\text { (NS) }\end{array}$ \\
\hline $\begin{array}{l}\text { Red Blood cell Count } \\
\text { (million/mm3) }\end{array}$ & $3.36 \pm 0.54$ & $3.80 \pm 0.66$ & $\begin{array}{l}0,0482 \\
(\mathrm{~S})\end{array}$ \\
\hline PCV (\%) & $26.92 \pm 3.83$ & $28.79 \pm 2.09$ & $\begin{array}{l}0.0937 \\
\text { (NS) }\end{array}$ \\
\hline $\operatorname{MCV}(\mathrm{fl})$ & $78.56 \pm 9.35$ & $77.22 \pm 11.14$ & $\begin{array}{l}0.6920 \\
\text { (NS) }\end{array}$ \\
\hline $\mathrm{MCH}(p g)$ & $24.4 \pm 3.82$ & $24.75 \pm 4.08$ & $\begin{array}{l}0.7730 \\
\text { (NS) }\end{array}$ \\
\hline $\mathrm{MCHC}(\mathrm{gm} / \mathrm{dl})$ & $30.13 \pm 4.29$ & $30.75 \pm 4.52$ & $\begin{array}{l}0.5767 \\
\text { (NS) }\end{array}$ \\
\hline Total WBC count & $2185 \pm 960$ & $9482 \pm 4925$ & $\begin{array}{l}0.0000 \\
\text { (HS) }\end{array}$ \\
\hline $\begin{array}{l}\text { Absolute Neutrophil } \\
\text { count }\end{array}$ & $974 \pm 646$ & $4431 \pm 1948$ & $\begin{array}{l}0.0000 \\
(\mathrm{HS})\end{array}$ \\
\hline $\begin{array}{l}\text { Absolute Lymphocyte } \\
\text { count }\end{array}$ & $960 \pm 505$ & $4340 \pm 3847$ & $\begin{array}{l}0.0007 \\
\text { (HS) }\end{array}$ \\
\hline $\begin{array}{l}\text { Absolute Monocyte } \\
\text { count }\end{array}$ & $135 \pm 105$ & $346 \pm 222$ & $\begin{array}{l}0.0012 \\
(\mathrm{HS})\end{array}$ \\
\hline Neutrophil \% & $42.67 \pm 18.18$ & $54.05 \pm 20.37$ & $\begin{array}{l}0.0160 \\
(S)\end{array}$ \\
\hline Lymphocyte \% & $46.28 \pm 17.71$ & $39.23 \pm 20.19$ & $\begin{array}{l}0.0983 \\
(\mathrm{NS})\end{array}$ \\
\hline Monocyte \% & $6.0 \pm 3.19$ & $3.61 \pm 1.16$ & $\begin{array}{l}0.0039 \\
(S)\end{array}$ \\
\hline $\begin{array}{l}\text { Platelet Count } \\
(\text { lac/mm3) }\end{array}$ & $1.84 \pm 0.72$ & $2.14 \pm 0.97$ & $\begin{array}{l}0.2157 \\
\text { (NS) }\end{array}$ \\
\hline CD4 count & $166 \pm 23$ & $385 \pm 156$ & $\begin{array}{l}0.0000 \\
(\mathrm{HS})\end{array}$ \\
\hline
\end{tabular}

Hematological parameters in AIDS and non-AIDS group showed hemoglobin \% in AIDS 8.50 \pm 1.40 and in non-AIDS $9.12 \pm 0.59(P=0.0878)$. There was no statistical significance. Red blood cell (mill/mm3) $3.36 \pm 0.54,3.80 \pm 0.66$ (S). This parameter was showed statistical significance as compared to previous. Packed cell volume(\%)26.92 $\pm 3.83,28.79 \pm 2.09$, Mean corpuscular volume (fl) $78.56 \pm 9.35,77.22 \pm 11.14$, Mean corpuscular hemoglobin (pg) $24.4 \pm 3.82,24,75 \pm 4.08$. These parameters were not showed any statistical significance as compared to previous.
Total WBC counts $2185 \pm 960,9482 \pm 4925$, Granulocytes counts $974 \pm 646,4431 \pm 1948$, Lymphocyte counts $960 \pm 505,4340 \pm$ 3847 ,Granulocyte $\% 42.67 \pm 18.18,54.05 \pm 20.37$, Platelet counts (lac/mm3) $1.84 \pm 0.72,2.14 \pm$ 0.97, CD4 counts /microliter $166 \pm 23,385 \pm 156$ (Table 3), Except platelet count, these values showed statistical significance.

Table 4: Bone marrow Cellularity findings in patients on ART and non-ART.

\begin{tabular}{|l|l|l|l|}
\hline $\begin{array}{c}\text { Bone Marrow } \\
\text { Cellularity }\end{array}$ & ART $(\mathbf{n = 6 2})$ & $\begin{array}{r}\text { Non-ART } \\
(\mathrm{n}=\mathbf{3 8})\end{array}$ & Total $(\mathrm{n}=\mathbf{1 0 0})$ \\
\hline Normocellular & $\begin{array}{l}36(58.06 \\
\%)\end{array}$ & $27(71.05 \%)$ & 63 \\
\hline Hypocellular & $\begin{array}{l}17(27.41 \\
\%)\end{array}$ & $05(13.15 \%)$ & 22 \\
\hline Hypercellular & $\begin{array}{l}09(14.51 \\
\%)\end{array}$ & $06(15.89 \%)$ & 15 \\
\hline
\end{tabular}

In the peripheral blood smear- various morphological abnormalities were detected in RBC like anisopoikilocytosis, basophilic stippling, acanthocytes. Polychromasia and nucleated RBCs were also detected. Amongst the WBC series pseudo-pelger-huet cells and activated lymphocytes were found in smear. Even, giant platelets were detected in some of the cases.Bone marrow morphology was assessed and analyzed considering features like adequacy, cellularity, myeloid to erythroid ratio, features of erythroid, myeloid and megakaryocytic series, lymphoid cells, plasma cells, macrophages, iron content, presence of abnormal cells, parasites, fungi and acid-fast bacilli.In patients on ART bone marrow were hypercellular, hypocellular, and normocellular in 09 (14.51\%), $17(27.41 \%)$, and $36(58.06 \%)$ respectively. In the non-ART group, bone marrow was hypercellular, hypocellular, and normocellular in 06(15.89\%), $05(13.15 \%), 27(71.05 \%)$ respectively. The bone marrow had been found normocellular in the majority cases of the non-ART group as compared to ART ( $p$-value $=0.9145$ ) [Table 4].

Table 5: Bone-Marrow cellularity of AIDS and Non-AIDS patients.

\begin{tabular}{|l|l|l|l|}
\hline \multicolumn{1}{|c|}{$\begin{array}{c}\text { Bone Marrow } \\
\text { Cellularity }\end{array}$} & $\begin{array}{c}\text { AIDS(n=37) } \\
\%\end{array}$ & $\begin{array}{c}\text { Non-AIDS(n=54) } \\
\%\end{array}$ & $\begin{array}{c}\text { Total(n=91) } \\
\%\end{array}$ \\
\hline Normocellular & $32(86.48)$ & $46(85.18)$ & $78(85.71)$ \\
\hline Hypocellular & $3(8.10)$ & $5(9.25)$ & $8(8.79)$ \\
\hline Hypercellular & $2(5.40)$ & $3(5.55)$ & $5(5.49)$ \\
\hline
\end{tabular}

In our study, we also found that most of the marrow was normocellular $85.71 \%$ of patients in AIDS and non-AIDS, hypercellular in $5.49 \%$, hypocellular in 
$8.79 \%$ in both the groups. This hypocellularity of bone marrow was due to serous fatty degeneration. [Table 5]

Photomicrogram 1: Showing features of dyserythropoiesis- megaloblastoid change, bi/multinucleation, nuclear budding, micronormoblast.

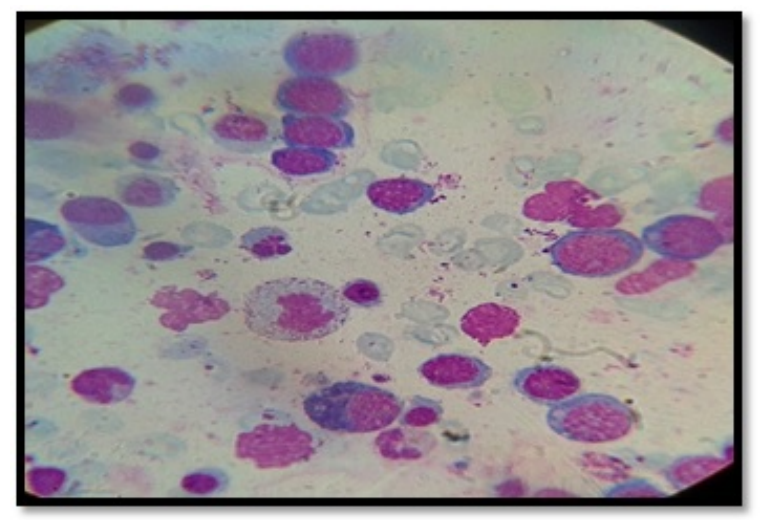

Dyserythropoiesis was found in the form of megaloblastoid change, binucleation/multinucleation,cytoplasmic vacuolation, nuclear budding, micronormoblastic change and ringed sideroblast [Photomicrogram 1].

Photomicrogram 2: Showing features of Granulocytic dysplasia- nuclear dysmorphism, hypogranulation, pseudo-pelger-huet anomaly.

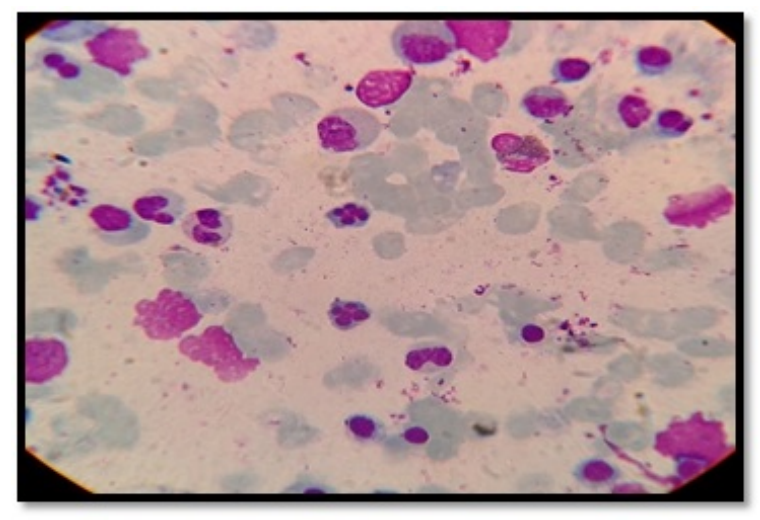

Amongst the patients with dysgranulopoiesis, various dysplastic features seen were nuclear dysmorphism, pseudo-pelger-huet anomaly,cytoplasmic vacuolation, hypogranulation and giant metamyelocytes [Photomicrogram 2].

Table 6: Myelodysplasia in bone marrow in HIV patients.

\begin{tabular}{|l|l|l|}
\hline \multicolumn{1}{|c|}{ Dysplasia } & \multicolumn{1}{|c|}{ AIDS $(\mathrm{n}=\mathbf{3 7}) \%$} & \multicolumn{1}{|c|}{ Non-AIDS $(\mathrm{n}=\mathbf{5 4}) \%$} \\
\hline No-Dysplasia & $24(64.86)$ & $48(88.88)$ \\
\hline
\end{tabular}

\begin{tabular}{|l|l|l|}
\hline Granulocytic & $07(18.91)$ & $02(3.70)$ \\
\hline Erythroid & $06(16.21)$ & $04(7.40)$ \\
\hline Megakaryocytes & $00(00.00)$ & $00(00.00)$ \\
\hline
\end{tabular}

Dysplasia was considered based on anemia and myelodysplasia was noted in two cell lines. Among the AIDS patients, dysplasia in above mentioned two cell lines (erythroid $16.21 \%$ and granulocytic $18.91 \%$ ) were more common than the non-AIDS patients (erythroid $7.40 \%$ and granulocytic 3.70 $\%)$. We did not get any case of dysmegakryopoiesis [Table 6].

Bar Diagram 1: Opportunistic infections and Bone Marrow abnormalities (apart from Myelodysplasia) in HIV patients.

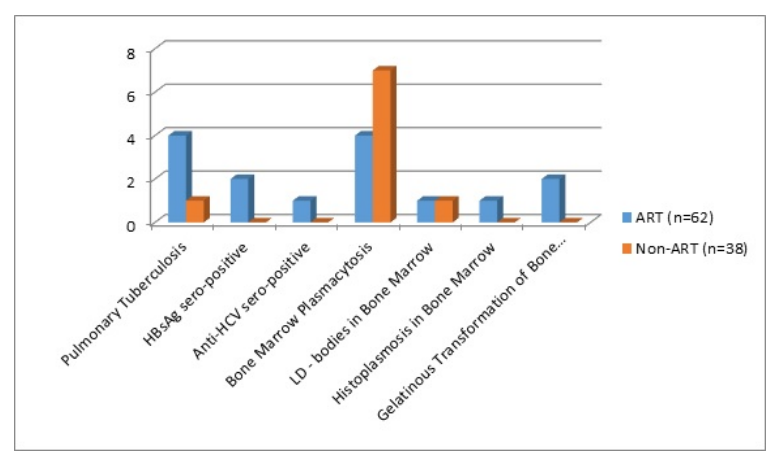

Out of 62 Cases, which were taking HAART, 4 patients with dysgranulopoiesis had underlying pathology of pulmonary tuberculosis, compared with 1 case belonging to a non-ART group $(n=38)$. [Bar Diagram 1]Plasmacytosis in the bone marrow had been a pretty common feature, both in ART( 4 cases) and non-ART ( 7 cases) groups.

Photomicrogram 3: Showing the presence of Histoplasma in Bone Marrow Aspiration Smear.

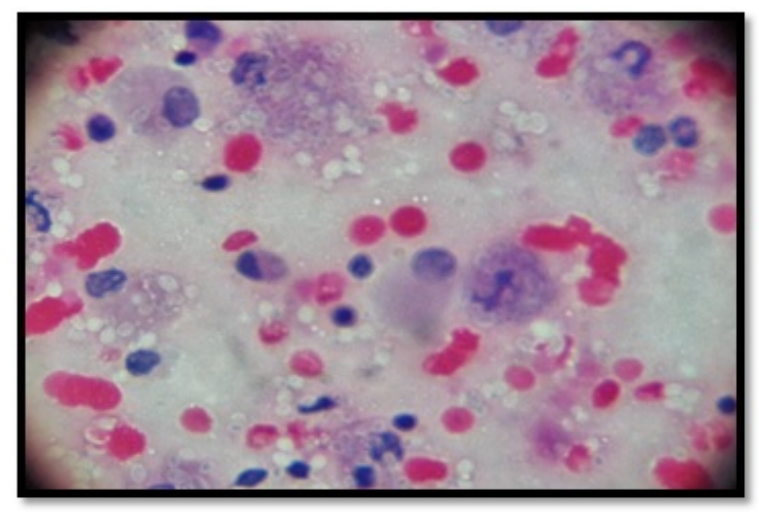

We got two interesting cases with opportunistic infections. The presence of LD bodies (one case each in ART and non-ART group) [Photomicrogram 
4] and Histoplasma (one case in ART group) had been appreciated [Photomicrogram 3].

Photomicrogram 4: Showing the presence of LD- Bodies in Bone Marrow Aspiration smears.

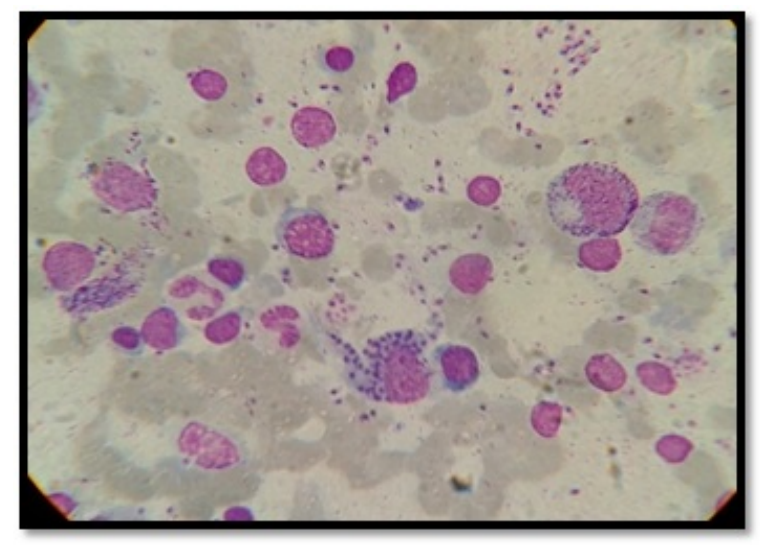

Gelatinous transformation of marrow could be noted in 2 cases in the ART group whereas seropositivity of HBsAg and anti-HCV could be identified in two and one patient on ART, respectively.

No underlying leukemia or lymphoma was detected in our study.

\section{Discussion}

Demographic analysis: The present study reveals that the population involved in occupations like long trip vehicle driving (eg. truck drivers), and labourers are the most vulnerable group for HIV infection. In our study, male preponderance can be noted with the commonest age group being 21 to 40 years. A study done by A.K Tripathi et al (2005, Feb), included 74 HIV- positive patients with a male to female ratio was $4: 1$, and the commonest age group was $20-40$ years with a range of 20 to 68 years [1].

Pathophysiology of Bone- marrow Changes in HIV infection: Several Pathophysiological factors play an important role in bone marrow abnormalities. It has been identified that HIV -1 virus mainly affects Stem cells and several progenitor cells.

Reduced colony growth factor has been demonstrated for granulocyte-macrophage progenitor cells (CFU-GM), multipotential hematopoietic progenitor cells (CFU-GEMM), and megakaryocyticprogenitor cells (CFU-MK), as well as early erythroid progenitor cells (BFU-E) and megakaryocytic colonies (CFU-Mg) in most patients with AIDS.
That defective progenitor cell growth might be secondary to suppressor $T$ cells is suggested by the observation that T-lymphocyte depletion enhances colony formation by progenitor cells in AIDS patients but not in normal individuals. The inhibition appears to be mediated by a serum antibody directed to an HIV structural protein. In addition, there is now evidence that CD34 progenitor cells from normal bone marrow and fetal hepatic hematopoietic cells can be infected with HIV in vitro although the extent of infection may be limited in asymptomatic patients. There has been an alteration of the T4:T8 ratio. The ratio is seen to be inversely proportional to HIV infectivity.[1]. As a result, in the peripheral blood picture, we found anemia, bi or pancytopenia.

Comparison of Hematological changes in our study with other studies: Patients were classified according to CD4 count in the line of NACO guidelines into two groups- CD4 count $<200 /$ cumm into AIDS group and $>200 /$ cumm into the non-AIDS group. In our study $40.65 \%$ of patients in AIDS (37 patients), while $59.34 \%$ in non -AIDS (54 patients), as we were able to do CD4 count only in 91 patients out of 100 patients.Our study reveals that anemia was one of the most common findings in HIV positive patients. Jerry L. et al (1984)showed thrombocytopenia was initially in $3(25 \%)$ patients and subsequently developed in 2 others. Patwardhan M.S et al (2002) showed thrombocytopenia in 65 patients (13\%) with average platelet count $0.92 \times 10$ (3)/ul[18].In our study thrombocytopenia on marrow showed increased megakaryocytes number secondary to increase peripheral destruction of the platelet. It is mainly due to auto-immune mediated destruction of platelet in peripheral blood.

Comparison of changes of Bone- Marrow cellularity in our study with other studies: In the ART group, bone marrow was normocellular in 36 patients and hypocellular marrow in 17 patients, which was due to patchy involvement mostly by fatty degeneration of bone marrow. Hypercellular marrow was in 9 patients because of erythroid hyperplasia. Whereas patients on Non-ART, normocellular bone marrow in 27 patients. Hypocellular marrow was found in 5 patients, hypercellular in 6 patients. The difference between the ART and Non-ART group found to be statistically insignificant $(P=0.2423)$. This finding is in concordance with the study done by Castellaet al, who reported normocellular bone marrow in 
$67.30 \%$, followed by the hypocellular bone marrow in $17.3 \%$ [9]. The variation in cellularity in our study from other studies could be explained by the fact reported in the literature that hypocellular bone marrow may be seen in the early stage of the disease but it is more likely to be normocellular or hypocellular in an advanced stage of disease[1]. Our study population is from hospitalized patients, hence more likely to be in an advanced stage of the disease.A study by Donald S. et al (1991) showed marrow hypercellularity in $52 \%$ of patients, hypocellularity in $13 \%$ of patients. Marrow cellularity was based on fat to cell ratio concerning patients' age. However, in HIV -infected patients, hypercellularity has only appeared when there is an increased number of non-hemopoietic cells such as lymphocyte, plasma cells and histiocytes [10]. Lionard et al (1987) conducted a similar study, showed in group A (seropositive with active infection and drug therapy), normocellular 15\%, hypocellular $8 \%$, hypercellular $77 \%$, while in group $B$ (seropositive with no active infection and no drug), normocellular $0 \%$, hypocellular $52 \%$, hypercellular 48\%[11]. Gonzales et al (1995) showed only hypocellular bone marrow in $65 \%$ HIV positive patients [12].

Comparison of Dysplastic changes of bone marrow in our study with other studies:The most important aspect of our study is to identify morphologically myelodysplastic features in the bone marrow of HIV infected patients. Pancytopenia in face of cellular marrow indicates ineffective erythropoiesis of bone marrow; it is an important feature of myelodysplasia.

The most common dysplastic change found was dysmyelopoiesis (18.91\% and $3.70 \%$, in AIDS and non-AIDS groups respectively), followed by dyserythropoietic (16.21\% and 7.40\%, in AIDS and non-AIDS groups respectively). Our study is in concordance with the study done by Tripathi et al and Karcheret al. However, some studies reported megakaryocytic and granulocytic series as the most common cell line involved respectively. We did not get any cases of dysmegakaryopoiesis $[1,13]$. A. K. Tripathi et al (2005) noted granulocytic,erythroid and megakaryocytic dysplasia 20\%,3\%,1\% respectively in Non-AIDS and AIDS groups [1]. Lionard I. et al (1986) showed myelodysplasia in the group $-A$ and group $-B,($ mention previously) Dysplasia of any type in $8(62 \%)$ out of 13 group $-A$, $9(43 \%)$ out of 21 in group $B$, erythroid 7 (54\%) in group $A, 9((43 \%)$ in group $B$, myeloid dysplasia
$5(38 \%)$ in group A and 5(24\%)in group B [11]. Various dyspoietic features seen in the erythroid series in our study were megaloblastoid change, bi/multinucleation, cytoplasmic vacuolation, nuclear budding, micronormoblast and ringed sideroblasts. Megaloblastoid changes seen in HIV related myelodysplasia is unrelated to serum cobalamin and folate levels, or drug therapy with zidovudine orfolate antagonists, although these drugs may accelerate it [1]. Dysplastic changes involving myeloid series, seen in our study include nuclear dysmorphism, giant metamyelocytes, cytoplasmic vacuolation,hypogranulation and pseudo-pelgerhuet anomaly. Direct infection of marrow precursors by HIV may contribute to these defects, although this issue remains controversial.

Comparison of opportunistic infections and other changes of bone marrow in our study with other studies: Commonest infection was found to be pulmonary tuberculosis; among them 4 patients also on HAART (Nevirapine, zidovudine) therapy. 2 cases were having seropositivity of HBsAg and 1 case having anti-HCV. These cases were on ART therapy.Plasma cells were often strikingly increased in the marrow of HIV infected patients seen in $31-85 \%$ of patients [14]. Our patient population had plasmacytosis in $12.08 \%$ of patients ( 4 cases of ART-group and 7 cases of the non-ART group). It might represent a physiological response to antigenic stimulation by viruses or other infective agents or may be secondary to dysregulated B-cell proliferation due to HIV [15]. Another interesting aspect of our study was to identify histoplasma (one case) and L-D bodies (2 cases, one case each from ART and non-ART group) in the bone marrow.Bone marrow aspirate stained by Giemsa showed oval globose yeast-like cells measuring 3-4 $\mathrm{mm} \times 2-3 \mathrm{~mm}$ in size, suggestive of $H$. capsulatum in proximity to irregular clusters of epithelioid cells showing vague granuloma formation. However, no giant cell (Langhans' or foreign body) on those aspirate slides.PAS stain revealed these yeast-like cells as bright eosinophilic structures. We have detected 2 cases of visceral leishmaniasis, where the Amastigote form of leishmania donovai was detected both extracellular and within histiocytes. Bone marrow findings of those two cases of visceral leishmaniasis are summarized below-

01. Presence of LD bodies

02. Decreased myeloid-erythroid ratio indicating relativesuppression of myelopoiesis. 
03. Increased number of plasma cells up to $10 \%$ indicatingincreased antibody formation.

04. Presence of giant metamyelocytes indicatingsuppression of cell division.

05. Presence of juvenile megakaryocytes indicatingthe increased formation of platelets to meet the demand causedby increased destruction in the hyperactive spleen.

06. Presence of micro-normoblasts in aggregates indicatingsplenic hyperactivity.

Gelatinous transformation of the bone marrow is characterized by fat cell atrophy, loss of hematopoietic cells, and the deposition of extracellular gelatinous substances [16]. We got 2 such cases in the background of hypocellular marrow. While it is not a specific disease, it is a sign of a generalized severe illness in a patient. Disease states that have been associated with gelatinous transformation are anorexia nervosa, alcoholism, malignancies, chronic heart failure, and HIV/AIDS. Mehta and colleagues observed that $29 \%$ of patients with AIDS in their study had gelatinous transformation or serous atrophy of the bone marrow [17].

\section{Conclusion}

Our purpose in performing this study was to observe manifestations of bone marrow abnormalities in terms of $\mathrm{Hb} \%$, total and differential count of WBC, platelet count and study of peripheral blood smear etc. We observed various myelodysplastic changes in two-cell lineages, both in patients taking HAART and not. We also observed the opportunistic infections in the bone marrow of AIDS patients inform of visceral leishmaniasis and disseminated histoplasmosis and gelatinous transformation of marrow. HIV infection should be included in the differential diagnosis of patients with secondary myelodysplasia. For confirmation and categorization, further cytogenetic and molecular genetic studies were to be done.

\section{Limitations of Study}

1) CD4 counts could not be done in all subjects due to technical problems.

2) We could not trace the contact or the source of HIV infection, as the population of the study was selected randomlyand they were coming from a vast geographical area and different socio-economical strata.
3) No follow up was done to review the haematological changes on HAART with improvement in CD4 counts.

\section{What does this study add to existing knowledge?}

Our study emphasized the need for a thorough examination of bone marrow in each case of HIV infection. It had been noticed that one of the underlying causes of Anemia/Pancytopenia might be Mylelodysplasia. Hypocelluarity of bone marrow is a common picture in the advanced stage and comparatively high incidences of myelodysplasia have been found in AIDS patients. Opportunistic infections like Leishmaniasis and disseminated Histoplasmosis often involve the bone marrow. So, any suspicious case of such infections needs a thorough examination of bone marrow.

\section{Author's Contribution}

Prof.(Dr.) Mamata Guha Mallick (Sinha): Concepts, Manuscript review, Guidance of research work. Dr. Soumya Kanti Pramanik: Literature Search, Data acquisition, statistics, Manuscript Preparation.

\section{Reference}

01. Tripathi AK, Misra R, Kalra P, Gupta N, Ahmad R. Bone marrow abnormalities in HIV disease. J Assoc Physicians India. 2005 Aug;53;705-10. [Crossref] [PubMed][Google Scholar]

02. Pande A, Bhattacharyya M, Pain S, Samanta A. Study of bone marrow changes in antiretroviral naive human immunodeficiency virus-infected anemic patients. Indian J Pathol Microbiol. 2011 JulSep;54(3)542-6. doi: 10.4103/0377-4929.85089 [Crossref][PubMed][Google Scholar]

03. Wang L, Mondal D, La Russa VF, Agrawal KC. Suppression of clonogenic potential of human bone marrow mesenchymal stem cells by HIV type 1putative role of HIV type 1 tat protein and inflammatory cytokines. AIDS Res Hum Retro viruses. 2002;18(13)917-31. doi: 10.1089/088922 202760265597 [Crossref][PubMed][Google Scholar]

04. McKenna RW, Risdall RJ, Brunning RD. Virus associated hemophagocytic syndrome. Hum Pathol. 1981 May;12(5)395-8. doi: 10.1016/s00468177(81)80019-6 [Crossref][PubMed][Google Scholar] 
05. Sitalakshmi S, Srikrishna A, Damodar P. Haematological changes in HIV infection. Indian J Pathol Microbiol. 2003 Apr;46(2)180-3. [Crossref] [PubMed][Google Scholar]

06. Diebold J, Molina T, Camilleri-Broët $S$, Le Tourneau A, Audouin J. Bone marrow manifestations of infections and systemic diseases observed in bone marrow trephine biopsy review. Histopathology. 2000 Sep;37(3)199-211. doi: 10.1046/j.1365-2559.2000.00965.x [Crossref] [PubMed][Google Scholar]

07. Biggar RJ, Rabkin CS. The epidemiology of AIDS--related neoplasms. Hematol Oncol Clin North Am. 1996 Oct;10(5)997-1010. doi: 10.1016/s08898588(05)70380-4 [Crossref][PubMed][Google Scholar]

08. Stein ME, Spencer D, Dansey R, Bezwoda WR. Biology of disease and clinical aspects of AIDSassociated lymphoma- a review. East Afr Med J. 1994 Apr;71(4)219-22. [Crossref][PubMed][Google Scholar]

09. Castella A, Croxson TS, Mildvan D, Witt DH, Zalusky R. The bone marrow in AIDS- A histologic, hematologic, and microbiologic study. Am J Clin Pathol. 1985 Oct;84(4)425-32. doi: 10.1093/ajcp/84.4.425 [Crossref][PubMed][Google Scholar]

10. Donald W. Northfelt, MD, Mayo Clinic, Scottsdale, Arizona, Hematologic Manifestations of HIV, Hematology. Am SocHematolEduc Program. 2003;294-313. [Crossref][PubMed][Google Scholar]

11. Zon LI, Arkin C, Groopman JE. Haematologic manifestations of the human immune deficiency virus (HIV). $\mathrm{Br}$ J Haematol. 1987 Jun;66(2)251-6. doi: $\quad$ 10.1111/j.1365-2141.1987.tb01307.x [Crossref][PubMed][Google Scholar]

12. González Aza C, Grilo Reina A, López Martín JC, Torre Sabariego A, Martínez Estéfano E, López Lacomba D, Herrera Díaz A, Moreno Garrido D. Alteraciones de la médulaóseaenadictos a drogas por vía parenteral seropositivos y seronegativos para el virus de la inmunodeficienciahumana [Changes in bone marrow among HIV-positive and HIV-negative parenteral drug addicts]. Med Clin (Barc). 1995 Jan 28;104(3)89-91. [Crossref] [PubMed][Google Scholar]
13. Karcher DS, Frost AR. The bone marrow in human immunodeficiency virus (HIV)-related disease, Morphology and clinical correlation. Am J Clin Pathol. 1991 Jan;95(1)63-71. doi: 10.1093/ajcp/95.1.63 [Crossref][PubMed][Google Scholar]

14. Sun NC, Shapshak $P$, Lachant NA, Hsu MY, Sieger L, Schmid $P$, ET AL. Bone marrow examination in patients with AIDS and AIDS-related complex (ARC), Morphologic and in situ hybridization studies. Am J Clin Pathol. 1989 Nov;92(5)589-94. doi: 10.1093/ajcp/92.5.589 [Crossref][PubMed][Google Scholar]

15. Rudresh K, Mukherjee T, Bhasin A, Mysorekar V, Modepalli N, Ahuja A. Bone marrow study in patients with human immune deficiency virus and acquired immune deficiency syndrome. Brunei Int Med J. 2011;7(3)148-56. [Crossref][PubMed] [Google Scholar]

16. Böhm J. Gelatinous transformation of the bone marrow: the spectrum of underlying diseases. Am J Surg Pathol. 2000 Jan;24(1)56-65. doi: 10.1097/00000478-200001000-00007 [Crossref] [PubMed][Google Scholar]

17. Mehta K, Gascon P, Robboy S. The gelatinous bone marrow (serous atrophy) in patients with acquired immunodeficiency syndrome, Evidence of excess sulfated glycosaminoglycan. Arch Pathol Lab Med. 1992 May;116(5)504-8. [Crossref][PubMed] [Google Scholar]

18. Spivak JL, Bender BS, Quinn TC. Hematologic abnormalities in the acquired immune deficiency syndrome. Am J Med. 1984 Aug;77(2)224-8. doi: 10.1016/0002-9343(84)90695-8 [PubMed][Google Scholar]
[Crossref] 